\title{
Equilibrium and kinetic studies of sorption of 2.4-dichlorophenol onto 2 mixtures: bamboo biochar plus calcium sulphate (BC) and hydroxyapatite plus bamboo biochar plus calcium sulphate (HBC), in a fluidized bed circulation column
}

\author{
Ahmed Hassan Alamin*, Lupong Kaewsichan \\ Prince of Songkla University, Department of Chemical Engineering, Faculty of Engineering, Hat Yai, Songkhla, 90112, \\ Thailand \\ "Corresponding author: e-mail: ahmed.10000@yahoo.com
}

\begin{abstract}
Sorption studies were carried out to investigate removal of 2.4-dichlorophenol (2.4-DCP) from aqueous solution in a fluidized bed by two types of adsorbent mixtures: BC (Bamboo char plus Calcium sulphate), and HBC (Hydroxyapatite plus Bamboo char plus Calcium sulphate); both manufactured in ball shape. The main material bamboo char was characterized by FTIR, DTA and SEM. The adsorption experiments were conducted in a fluidized bed circulation column. Adsorption, isotherms and kinetic studies were established under $180 \mathrm{~min}$ operating process time, at different initial 2.4-DCP solution concentrations ranging from $5-10 \mathrm{mg} / \mathrm{L}$, and at different flow rates ranging from $0.25-0.75 \mathrm{~L} / \mathrm{min}$. The data obtained fitted well for both the Langmuir and Freundlich isotherm models; indicating favorable condition of monolayer adsorption. The kinetics of both adsorbents complies with the pseudo second-order kinetic model. BC was proven a new effective composite and low cost adsorbent which can be applied in the field of wastewater treatment, and it can also play an important role in industry water treatment.
\end{abstract}

Keywords: 2.4-dichlorophenol, bamboo biochar, hydroxyapatite, calcium sulphate, adsorption.

\section{INTRODUCTION}

Phenolic compounds pose a major worldwide environmental health problem concerning industries handling phenol and metal process. Chlorophenol is a group of chemical, of which chlorines (between one and five) have been added to phenol ${ }^{1}$. Main pollution source containing chlorophenols are wastewaters released from industries producing pesticides, paints, solvents, pharmaceuticals, plastics, wood, paper and pulps, as well as water disinfecting process ${ }^{2}$. In addition, phenolic derivatives are largely used as intermediates in productions of plastics, colors, pesticides, insecticides, etc. ${ }^{3}$. However, phenol containing water-when chlorinated during disinfection of water-results in formation of chlorophenol ${ }^{4}$.

Chlorophenols and related compounds are toxic to humans and aquatic lives, which are carcinogenic, mutagenic, and resistant to biodegradation ${ }^{5}$. Phenols are considered as priority (persistence bioaccumulation and toxicity (PBT)) pollutants since they are harmful to organisms at low concentrations and many of them have been classified as hazardous pollutants because of their potential to harm human health. The United States Environmental Protection Agency (USEPA) and the European Union (EU) have designated phenols as priority pollutants ${ }^{6}$. Thus, removal of phenol from drinking water is of great importance, and has been receiving particular concerns in the last few decades?

Treatment technologies, depending on the load of phenol compound in wastewater, are either physiochemical or biological ${ }^{8}$. Some conventional methods used to remove phenol from aqueous solutions are: adsorption; precipitation and coagulation; sedimentation; filtration; membrane separation; chemical oxidation; ion exchange, and reverse osmosis?.

Phenol can be removed effectively through adsorption process using a variety of adsorbents ${ }^{10}$, but use of bamboo biochar is seldom mentioned. Various functional groups on bamboo biochar surface contribute to a unique and specific uptake for different molecules species ${ }^{11}$. Furthermore, it is well known that nano-size adsorbents, including hydroxyapatite, possess excellent surface properties, such as large accessible internal and external surface and have large surface area ${ }^{\mathbf{1 2}}$, bamboo biochar is a nano-size adsorbent. Bamboo biochar is a very fine adsorbent. It is obtained from burning of bamboo. The char is then ground into very fine powders; the pore sizes are approx. $2-50 \mathrm{~nm}^{\mathbf{1 3}}$.

A new composite material made from bamboo biochar plus calcium sulphate (BC), can be used as an adsorbent in that calcium sulphate plays a role on its hydrophilic property ${ }^{14}$. Hydroxyapatite, by itself or together with calcium sulphate - better known for their combined properties in the medical profession, particularly in bone surgery and bone treatment ${ }^{15}$, has reportedly been used more in the removal of heavy metals ${ }^{\mathbf{1 6}}$, but less so in the removal of phenols ${ }^{17}$. As far as we know no literature has reported on the use of $\mathrm{HBC}$ in the removal of phenols either.

Fluidized-bed reactors have received considerable attention and wide utilization in wastewater treatment due to several advantages ${ }^{18}$. First, this type of reactor renders a more intensive contact between liquid and solid phase causing high mass transfer, a high reaction rate, and small external mass transfer resistance between solid and liquid phase. Second, it could eliminate operating problems such as bed clogging and high pressure drop, which occur in packed-bed systems operations. Third, it is a high efficient, simple, stable and economical operation compared to other reactor configurations ${ }^{18}$.

The objective of this study was to investigate the adsorption of 2.4-dichlorophenol (2.4-DCP) in aqueous solution (wastewater) onto two types of ball-shape adsorbents: $\mathrm{BC}$ and $\mathrm{HBC}$, in a laboratory-scale fluidized-bed 
circulation column. Adsorption isotherms, Langmuir and Freundlich were investigated. Moreover, adsorption kinetics pseudo-first and pseudo-second order were calculated for comparison.

\section{MATERIAL AND EXPERIMENTAL METHODS}

\section{Adsorbent properties and preparation}

Bamboo biochar (BB), bamboo, obtained locally near our laboratory, was cleaned, chopped into $10 \mathrm{~mm} \times 10$ $\mathrm{mm}$ pieces, and dried. One hundred grams of the sample was put onto a sieve tray and put into a stainless steel reactor $450 \mathrm{~mm}$ long, $110 \mathrm{~mm}$ in diameter. The reactor was then flushed with nitrogen gas at a pressure of 5 $\mathrm{kPa}$ to remove air. It was then put inside a furnace. Pyrolysis process then started; temperature inside the furnace was raised at an average rate of $20^{\circ} \mathrm{C} / \mathrm{min}$ until it reached $500^{\circ} \mathrm{C}$, then maintained for 4 hours. After the system was allowed to cool overnight, bamboo biochar was collected. The BB, was then ground into very fine powder to be used in this study as the main material. Hydroxyapatite (HAP), and 2.4-DCP were purchased from Sigma-Aldrich Co. LLC, while Calcium sulphate (CS) was from Aldrich Chemicals. BB was mixed with $\mathrm{CS}$ to form an adsorbent composite BC, and with HAP and $\mathrm{CS}$ to form another adsorbent composite $\mathrm{HBC}$. The weight ratio of $\mathrm{BB}: \mathrm{CS}$ is $0.62: 0.38$, and that of $\mathrm{BB}: \mathrm{HA}-$ $\mathrm{P}: \mathrm{CS}$ is $0.46: 0.27: 0.27$. A glue, prepared from polyvinyl alcohol (PVA) having a molecular weight MW of 22.000, was added to the mixtures to manufacture ball-shape adsorbents. Table 1 details some characteristics of BC and HBC. The concentration of residual phenol was determined using a double beam UV-Vis spectrophotometer (Shimadzu UV-1601 Spectrophotometer, Japan) at wave length $765 \mathrm{~nm}$. Fourier transforms infrared spectroscopies (FTIR) (Bomem, MB 100) were carried out to identify the functional groups of the biochar. DTA for thermal stability of BB was analyzed. Scanning electron microscopy (SEM) was conducted with a Hitachi JSM-6700F SEM to observe the surface microstructures of the fresh Bamboo biochar.

\section{Adsorbate properties and preparation}

A stock solution of 2.4-DCP was obtained by dissolving it in double distilled water. Desired solutions of phenol were prepared using appropriate subsequent dilutions of the stock solution. The range of concentration of the phenol prepared from the standard solution varied between 5-10 $\mathrm{mg} / \mathrm{L}$ as 2.4-DCP. The $\mathrm{pH}$ of the solutions was adjusted to 6.5 by $0.1 \mathrm{~N} \mathrm{NaOH}$ and $0.1 \mathrm{~N} \mathrm{HCl}$ solutions.

\section{Experimental method}

The study of 2.4-DCP adsorption was carried out in laboratory scale; a circulation fluidized bed reactor was used to improve mixing and homogeneity. The experimental system consisted of a reactor column, a water reservoir and a peristaltic pump as shown in Figure 1. The reactor's outside diameter is $50 \mathrm{~mm}$ and its height is $240 \mathrm{~mm}$. This reactor of the fluidized-bed column, having an effective volume of $470 \mathrm{ml}$, was made from transparent acrylic material. A mesh screen was fit at the top of the fluidized circulation column in order to capture the solid coming out of the column. A conical distributor was placed at the bottom to ensure proper distribution of fluid. Aqueous solutions of phenol were continuously fed with an upward flow at different flow rates, from 250 to $750 \mathrm{ml} / \mathrm{min}$. The liquid effluent stream was recycled to the hold-up tank. Three liters of the phenolic aqueous solution was treated with adsorbent of $3 \mathrm{~g}$ for each adsorbent. Adsorptions of the 2.4-DCP onto adsorbent $\mathrm{BC}$ and adsorbent $\mathrm{HBC}$ were compared. Aqueous solution of 2.4-DCP flowed through the adsorbents in the fluidized bed column and recycles back to the hold-up tank. Samples, approx. $10 \mathrm{ml}$ each, were taken from this closed-loop stream just before the effluent reaches the hold-up tank. Sampling starts at very close to time zero, and thereafter every $15 \mathrm{~min}$. Each test lasts $3 \mathrm{~h}$ or $180 \mathrm{~min}$, and thus there are 13 samples taken in each experiment. The suspensions samples in all studies were filtered through $0.45 \mu \mathrm{m}$ syringe membrane filters. All the experiments were conducted in triplicates for statistical analysis.

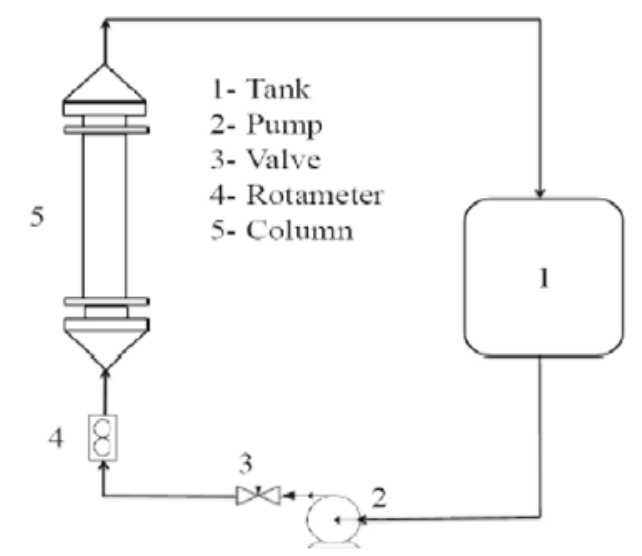

Figure 1. Process diagram

\section{RESULTS AND DISCUSSION}

\section{Fourier Transform Infrared (FTIR) analysis}

The progress for the pyrolysis process of BB was tracked and investigated by FTIR analysis which is a wavenumber technique. Sample discs were prepared by mixing ovendried $\left(\right.$ at $\left.105^{\circ} \mathrm{C}\right) \mathrm{BB}$ samples with spectroscopy-grade $\mathrm{KBr}$ in an agate mortar. Infrared spectra of wavenumbers (4000-400 $\mathrm{cm}^{-1}$ ) were recorded using a Nicolet IR100

Table 1. Outstanding Characteristics of Biochar plus Calcium sulphate (BC) and Hydroxyapatite plus BC (HBC)

\begin{tabular}{|l|c|c|}
\hline Characteristics & BC & HBC \\
\hline Dry specific weight & $0.771 \pm 0.001$ & $0.89 \pm 0.001$ \\
\hline TOC, $[\mathrm{g} / \mathrm{kg}]$ & 409.92 & 301.21 \\
\hline Ash content, [\%] & $34.23 \pm 0.16$ & $48.35 \pm 0.13$ \\
\hline Total-N, [\% w/w] & $0.300 \pm 0.012$ & $0.224 \pm 0.004$ \\
\hline Tot $-\mathrm{P},[\%]$ & $0.04 \pm 0.00$ & $2.09 \pm 0.00$ \\
\hline $\mathrm{pH}$ & $7.47 \pm 0.03$ & $7.18 \pm 0.04$ \\
\hline
\end{tabular}


FTIR spectrometer that was equipped with a TGS/ PE detector and a silicon beam splitter with $1 \mathrm{~cm}^{-1}$ resolution. Figure 2 shows the FTIR spectrum containing tracks of wavenumbers related to many functional groups of the $\mathrm{BB}$. Biochar produced at $500^{\circ} \mathrm{C}$ clearly revealed changes of functional groups on the surface. With increasing pyrolysis temperature, bands assigned to $\mathrm{O}-\mathrm{H}$ should have wavenumber close to $\left(3400 \mathrm{~cm}^{-1}\right)$. For the BB sample the $\mathrm{O}-\mathrm{H}$ band of hydroxyl group was found at $\left(3461 \mathrm{~cm}^{-1}\right)$, and the peak at $\left(2830 \mathrm{~cm}^{-1}\right)$ is assigned to $\mathrm{C}-\mathrm{H}$ of aldehydes. Aliphatic was lowered markedly by $\mathrm{C}-\mathrm{H}$ at wavenumbers $\left(2921.21-2855 \mathrm{~cm}^{-1}\right)$, indicating decreases of labile aliphatic compounds in the biochar with rising pyrolysis temperature and a possible occurrence of demethoxylation, demethylation, and dehydration of lignin.

The loss of $\mathrm{OH}$ and aliphatic groups explain the enhanced pore formation, exceptionally for a high pyrolysis temperature; and this hypothesis was consistent with the results of increased surface area. The two functional groups, asymmetric $\left(2921.21 \mathrm{~cm}^{-1}\right)$ and symmetric $\left(2855 \mathrm{~cm}^{-1}\right) \mathrm{C}-\mathrm{H}$ bands, were associated with aliphatic functional groups. Intense bands belonging to aliphatic $\mathrm{CH}_{2}$ become less with rising temperature; denoting lower contents of nonpolar groups.
The intensity of the band at $\left(1690-1591.73 \mathrm{~cm}^{-1}\right)$ (aromatic $\mathrm{C}=\mathrm{C}$ and $\mathrm{C}=\mathrm{O}$ of conjugated ketones and quinones) also diminished with rising temperature. The peak at $\left(1513.55 \mathrm{~cm}^{-1}\right)$ represents the $\mathrm{C}=\mathrm{C}$ ring of lignin, while the bands at $\left(1434.91 \mathrm{~cm}^{-1}\right)$ aromatic $\mathrm{C}=\mathrm{C}$ and $\left(885 \mathrm{~cm}^{-1}\right)$ out-of-plane deformation by aromatic $\mathrm{C}-\mathrm{H}$ groups might be caused by carbonates. Several outstanding peaks at $\left(1248.6-1000 \mathrm{~cm}^{-1}\right)$ were assigned to $\mathrm{C}-\mathrm{O}$ and $\mathrm{C}-\mathrm{C}$, and these peaks lessen markedly, probably due to losses of polysaccharides during pyrolysis. Moreover, the sharp band at $\left(1372 \mathrm{~cm}^{-1}\right)$ confirmed the existence of a $\mathrm{C}-\mathrm{O}$ bond on $\mathrm{BB}$, reinforcing the interaction with the carboxyl groups.

\section{Differential thermal analysis (DTA)}

Thermal stability of the BB was investigated by DTA analysis. The BB sample generally showed three main peaks for weight loss in the temperature due to range $25-800^{\circ} \mathrm{C}$ in Figure 3 . The first strong peak among the three peaks, at $75-96.17^{\circ} \mathrm{C}$, is assigned to the evaporation procedure of adsorbed water molecules. The second weak peak in the range $280-294^{\circ} \mathrm{C}$ indicates dissociation of the surfaces. And the third broad peak, appearing in the range $402-570^{\circ} \mathrm{C}$, could originate from the further carbonization process of the $\mathrm{BB}$. Above this range, a new peak is found at $814^{\circ} \mathrm{C}$.

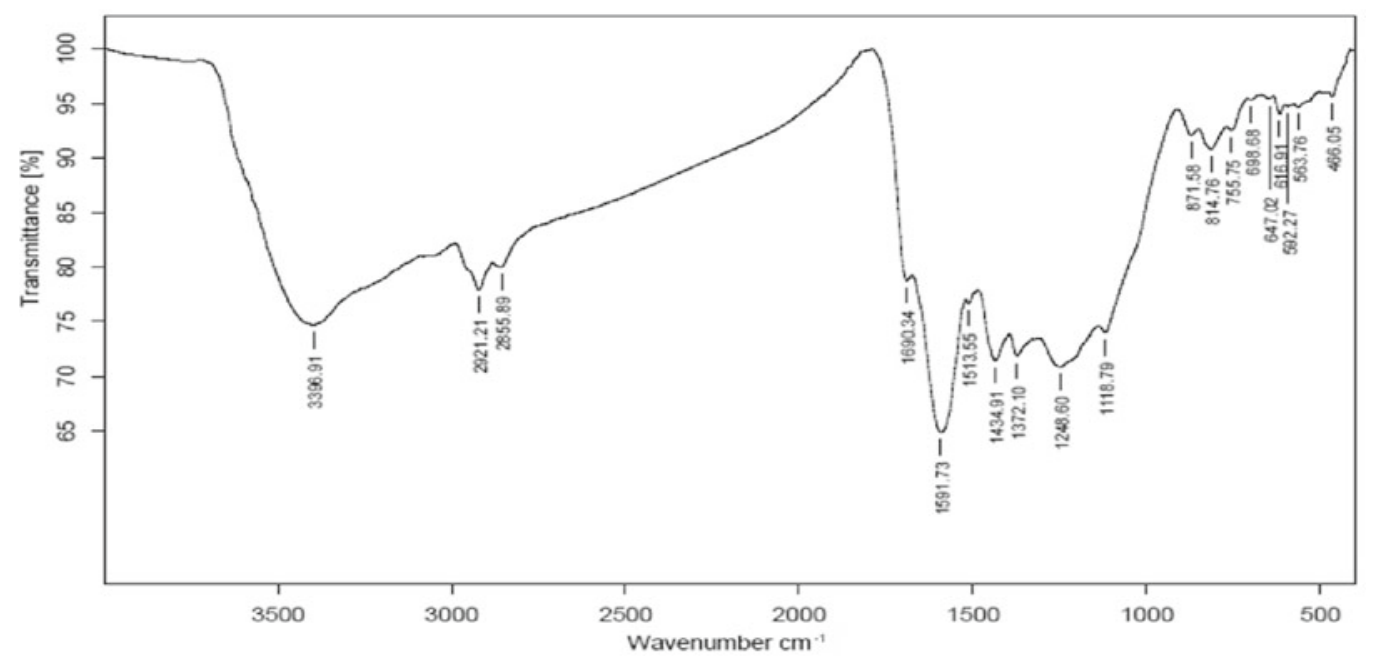

Figure 2. Characteristics of BB from FTIR analysis

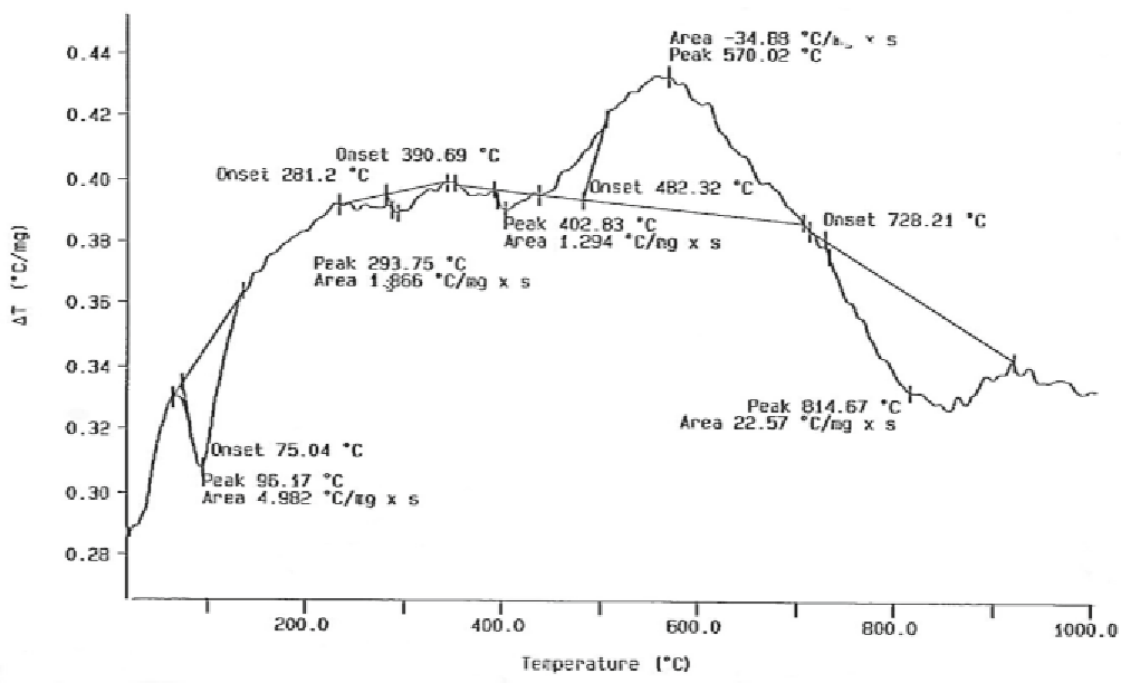

Figure 3. Characteristics of BB from DTA analysis 


\section{Scanning electron microscope images (SEM)}

SEM result on BB characteristics showed its morphology and elemental composition. There were large internal surface and porous structures at different Figure 4(a), and Figure 4(b). Figure 4(c), at x500 magnification, showed an average porous opening of $38.67 \mu \mathrm{m}$. Elemental percent compositions of the $\mathrm{BB}$ were evaluated by SEM mapping technique; results as shown in Table 2.
6-10, though with a sharp drop at $\mathrm{pH}$ 4. The drop in adsorption was sharper for $\mathrm{HBC}$ in the alkaline region while the drop was a little sharper for $\mathrm{BC}$ in the acidic region. Chlorophenols are weakly acidic, and $\mathrm{pH}$ has a significant effect on the degree of ionization of 2.4DCP and the adsorbent surface properties ${ }^{19}$.

The surface charge of the $\mathrm{BC}$ and $\mathrm{HBC}$, were negative in the pH-range between 3-10, see Figure 5. The ionic

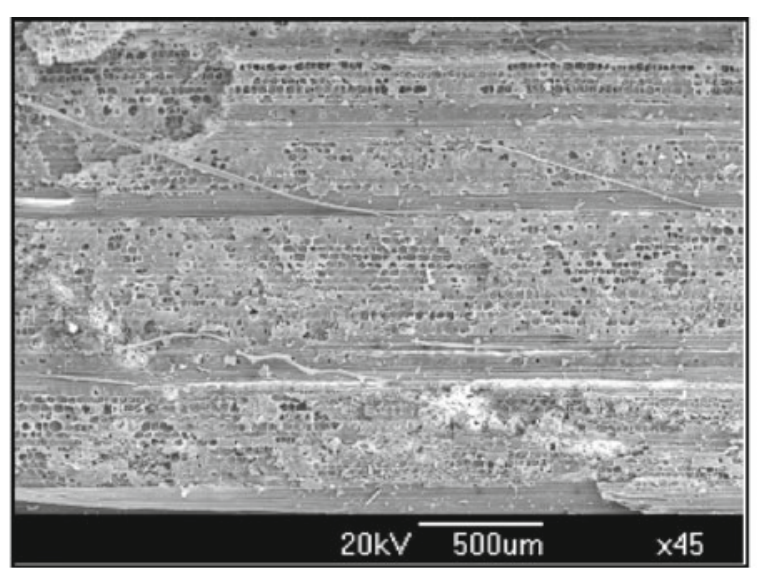

(a)

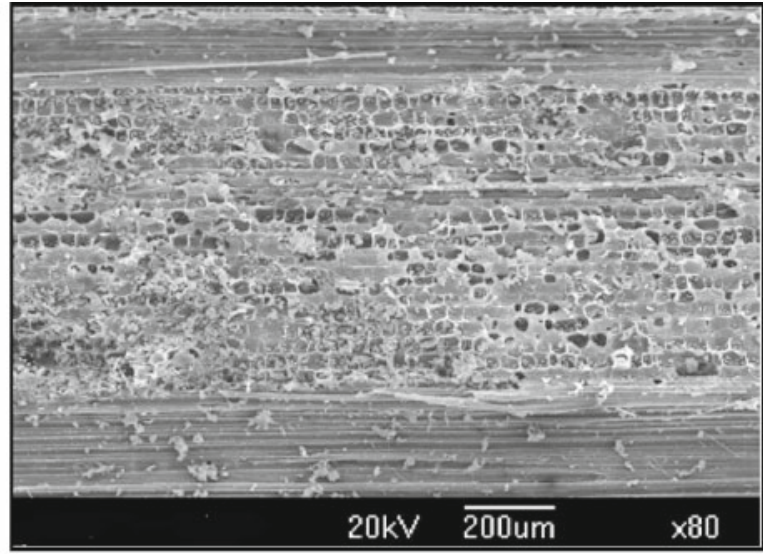

(b)

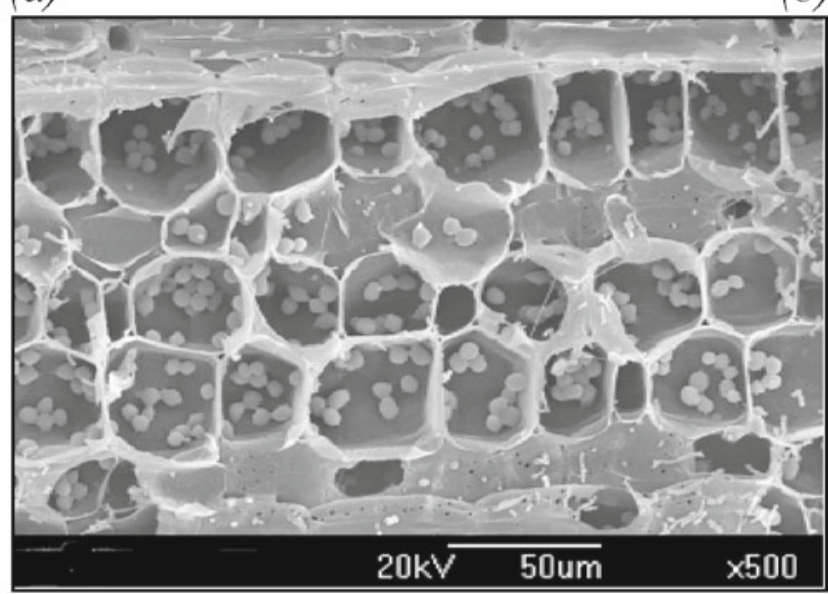

(c)

Figure 4. SEM of the bamboo biochar

Table 2. Elemental percent compositions of the BB were evaluated by SEM

\begin{tabular}{|l|c|}
\hline Elements & Amounts \% \\
\hline $\mathrm{C}$ & 59 \\
\hline $\mathrm{S}$ & 1.55 \\
\hline $\mathrm{K}$ & 30.5 \\
\hline $\mathrm{Cl}$ & 9.4 \\
\hline
\end{tabular}

\section{Effect of initial pH solution on 2.4-DCP adsorption}

Adsorbent behaviour of $\mathrm{BC}$ and $\mathrm{HBC}$ on the adsorption of 2.4-DCP were studied from adjustment effect of the initial $\mathrm{pH}$ between 3 to 10 at room temperature of $28^{\circ} \mathrm{C}$ while the initial concentration of 2.4-DCP solution of $10 \mathrm{mg} / \mathrm{L}$ was constantly maintained for both adsorbents. As shown in Figure 5, the removal rates of the 2.4-DCP were lower on both ends of the $\mathrm{pH}$ region. Different behavior trends were observed for the two different adsorbents. For HBC adsorbent, the maximum 2.4-DCP percent removal of $60 \%$ was at $\mathrm{pH}$ 6 , and its rates declined to $45-50 \%$ on either side. For $\mathrm{BC}$ adsorbent, the maximum removal percent of nearly $40 \%$ was at $\mathrm{pH} 8$, but was rather stable between $\mathrm{pH}$ fraction of chlorophenol ions increases with increasing $\mathrm{pH}$, and chlorophenol could be expected to become negatively charged as $\mathrm{pH}$ increases ${ }^{19}$, with a constant $\mathrm{pKa}$ value of 7.89 for the 2.4-DCP solution ${ }^{20}$. Non-dissociated form activated by the $\mathrm{OH}^{-}$and $\mathrm{Cl}^{-}$dominates

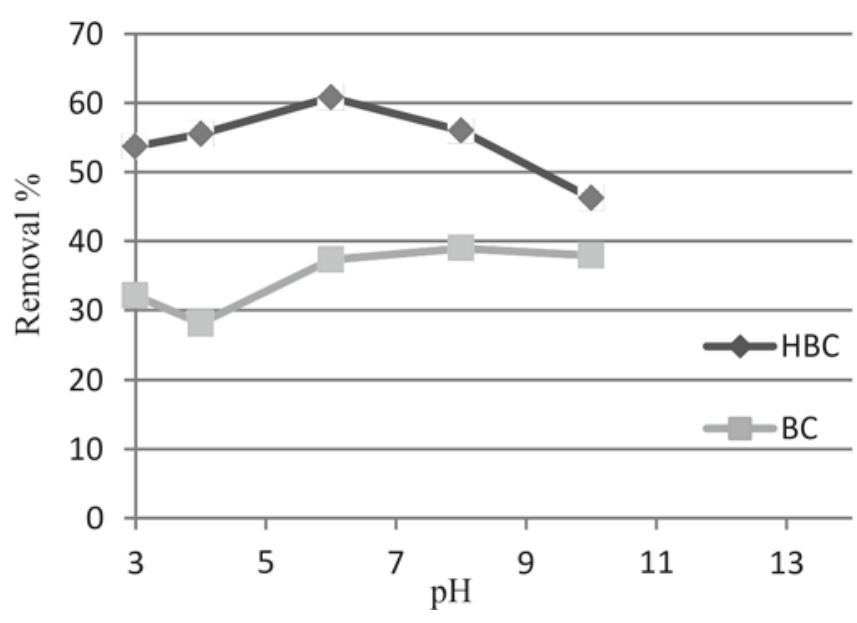

Figure 5. Percentage of removal vs. initial $\mathrm{pH}$ solution of 2, 4-DCP adsorption 
the overall sorption of chlorinated phenols on organic sorbents ${ }^{2}$. The slow and low removal percent of 2.4-DCP at highest $\mathrm{pH}$ could have been resulted from competition between the $\mathrm{OH}^{-}$ions and the ionic species of 2.4-DCP, hence reducing the 2.4-DCP removal ${ }^{1}$.

\section{Effect of contact time of fluidization}

The dependency on time on the efficiency of the removal 2.4-DCP was studied at time intervals up to $180 \mathrm{~min}$ at room temperature. At the initial stage the adsorbents have more available pore space on the surface and hence were ready for adsorption. Adsorption gradually increases depending on the accumulation of phenol on the adsorbents surface during this time. As a result, the remaining vacant surface sites are difficult to be occupied due to formation of similarly charged particles which exert repulsive forces between the phenol molecules on the solid surface and in the bulk phase ${ }^{21}$. Besides, phenol molecules are very small in size and can easily diffuse into internal pores until they become saturated; which will reduce the driving force for mass transfer between the bulk liquid phase and the solid phase over time ${ }^{11}$. Figure 6 depicts the effect of time on the percentage removal and the result was that the equilibrium time for either adsorbent was reached at approx. $180 \mathrm{~min}$; the authors had conducted up to $6 \mathrm{hrs}$ and found no significant increase in percentage removal. However, adsorption of 2.4-DCP employing either BC or $\mathrm{HBC}$ increased slowly to equilibrium, particularly the BC. At equilibrium, the removal percent were approx. $68 \%$ for $\mathrm{HBC}$, and $53 \%$ for $\mathrm{BC}$.

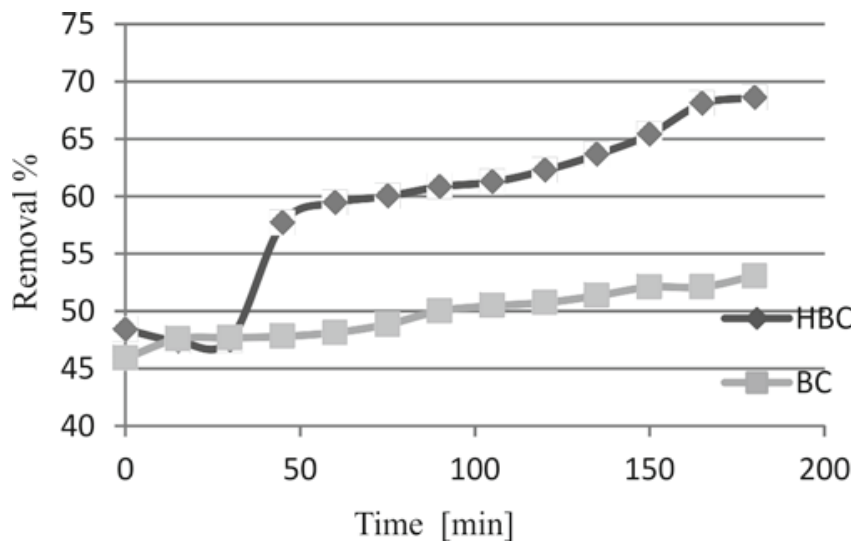

Figure 6. Percentage of removal 2, 4-DCP vs. contact time of circulation fluidization

\section{Effect of flow rate of 2.4-DCP solution}

The effect of different flow rate was investigated for adsorption of 2.4-DCP from aqueous solution employing the two adsorbents. Experiments were carried out at room temperature with flow rate in range of $250-750$ $\mathrm{ml} / \mathrm{min}$ while other variables were kept constant (solute $\mathrm{pH}$ of $6.5,3 \mathrm{~g}$ of adsorbent, $7.5 \mathrm{mg} / \mathrm{L}$ of the $2.4-\mathrm{DCP}$ initial concentration). From Figure 7, the percentage removal of the 2.4-DCP solution using $\mathrm{BC}$ adsorbent declined with increasing flow rate of the solution, whereas for HBC it was the opposite. The behavior for the $\mathrm{BC}$ can be explained by insufficient residence time of the solute in the column; the residence time decreased with increasing flow rate, leading to insufficient time for diffusion of the solution into the pores of the $\mathrm{BC}$ adsorbent and thus limiting the number of available active

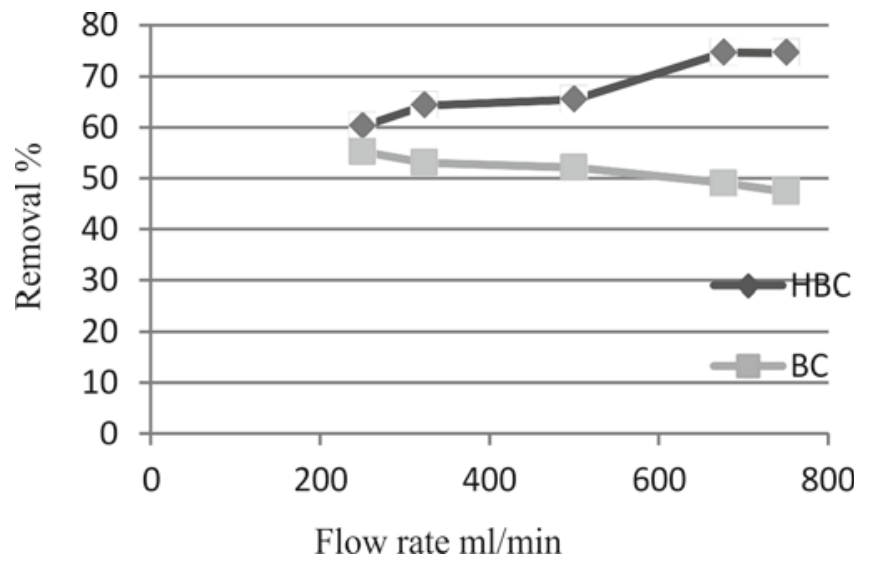

Figure 7. Percentage of removal vs. flow rate of 2.4-DCP solution

sites for adsorption, reducing the adsorbed amount of the aqueous solution since much solute left the column before equilibrium occurs ${ }^{22}$. In case of adsorbent HBC, the removal capacity increased imperceptibly below flow rate of $500 \mathrm{ml} / \mathrm{min}$, except at 250 to $300 \mathrm{ml} / \mathrm{min}$. Beyond flow rate of $500 \mathrm{ml} / \mathrm{min}$ the removal capacity rose rapidly to another plateau; the reason is that at higher flow rate, the rate of mass transfer tends to increase.

\section{Effect of initial concentration of 2.4-DCP solution}

Studies were carried out at room temperature to investigate the effect of initial concentrations, from 5-10 $\mathrm{mg} / \mathrm{L}$ of 2.4-DCP, on adsorption at fixed parameters: $\mathrm{pH}$ of 6.5 , adsorbent weight of $3 \mathrm{~g}$, flow rate of $500 \mathrm{ml} /$ min. It can be noted from Figure 8 that at lower initial concentration the capacities of sorption for both $\mathrm{BC}$ and $\mathrm{HBC}$ increased with increasing initial concentration, and then rose slowly for $\mathrm{BC}$ or plateau off for HBC. This is due to the raising of the mass transfer driving force and thus the rate at which 2.4-DCP molecules pass from the bulk solution to the particle surface. However, when the initial concentration went beyond $9 \mathrm{mg} / \mathrm{L}$ the absorbents behaved differently; the percentage of removal for the $\mathrm{BC}$ rose up a little, whereas for the HBC it dropped.

From the experiment, the highest percentage of removal for $\mathrm{HBC}$ was approx. $75 \%$ at $7.5 \mathrm{mg} / \mathrm{L}$ initial concentration. For adsorbent $\mathrm{BC}$, the maximum percentage of removal was at $56 \%$ at $10 \mathrm{mg} / \mathrm{L}$. The performance of adsorbent $\mathrm{HBC}$ is better than $\mathrm{BC}$ because the former has more specific surface area and more macro porous

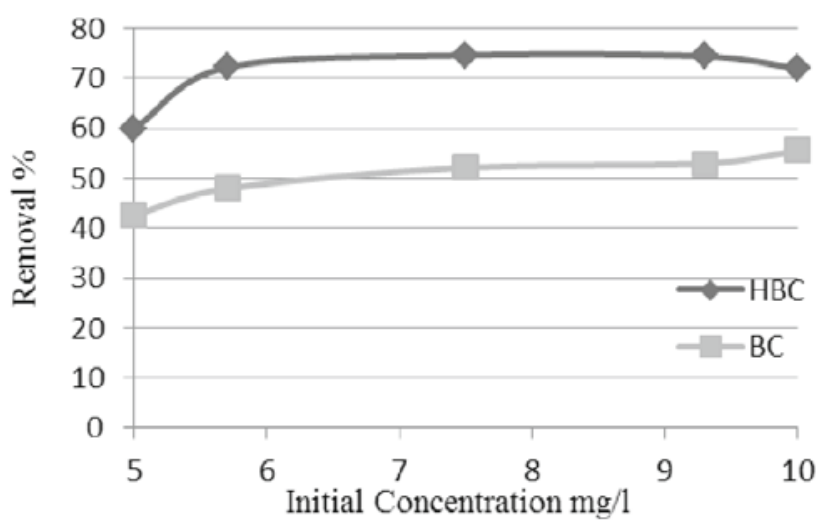

Figure 8. Percentage of removal vs. initial concentration of 2 , 4-DCP solutions 
structures. However, BC performance is at approx. 75\% of that obtained using HBC.

\section{Adsorption isotherms}

Isotherms are very important and essential for the understanding of adsorption system mechanism, and two models, Langmuir and Freundlich, were applied in this study to investigate the performance of the $\mathrm{BC}$ and HBC adsorbents.

The Langmuir model is based on assumptions of adsorption homogeneity such as equal available adsorption sites, monolayer surface coverage, and no interaction between adsorbed species ${ }^{23}$, and is described in Equation 1:

$\frac{\mathrm{c}_{\mathrm{e}}}{\mathrm{q}_{\mathrm{e}}}=\frac{1}{\mathrm{~b} \mathrm{q}_{\max }}+\frac{\mathrm{c}_{\mathrm{e}}}{\mathrm{q}_{\max }}$

Where $\mathrm{q}_{\mathrm{e}}$ and $\mathrm{q}_{\max }$ are the observed and maximum uptake capacities in $\mathrm{mg} / \mathrm{g} ; \mathrm{C}_{\mathrm{e}}$ is the equilibrium concentration in $\mathrm{mg} / \mathrm{L}$; and $\mathrm{b}$ is the equilibrium constant in $\mathrm{L} / \mathrm{mg}$.

The plots of versus are shown in Figure 9, and the calculated results in Table 3. It can be seen from the Table that the correlation coefficients were good for both adsorbents; with $\mathrm{HBC}$ a little better. And hence the Langmuir isotherm model is acceptable.

Table 3. Isotherm parameters for sorption of 2.4-DCP by different adsorbent

\begin{tabular}{|l|c|c|c|c|c|c|}
\hline \multirow{2}{*}{ Adsorbent } & \multicolumn{3}{|c|}{ Langmuir } & \multicolumn{3}{c|}{ Freundlich } \\
\cline { 2 - 7 } & $\mathrm{q}_{\max }$ & $\mathrm{b}$ & $\mathrm{R}^{2}$ & $\mathrm{~K}_{f}$ & $\mathrm{n}$ & $\mathrm{R}^{2}$ \\
\hline $\mathrm{BC}$ & 10.69 & 0.0350 & 0.9461 & 0.302 & 0.79 & 0.9650 \\
\hline $\mathrm{HBC}$ & 16.37 & 0.0315 & 0.9699 & 0.410 & 0.80 & 0.9827 \\
\hline
\end{tabular}

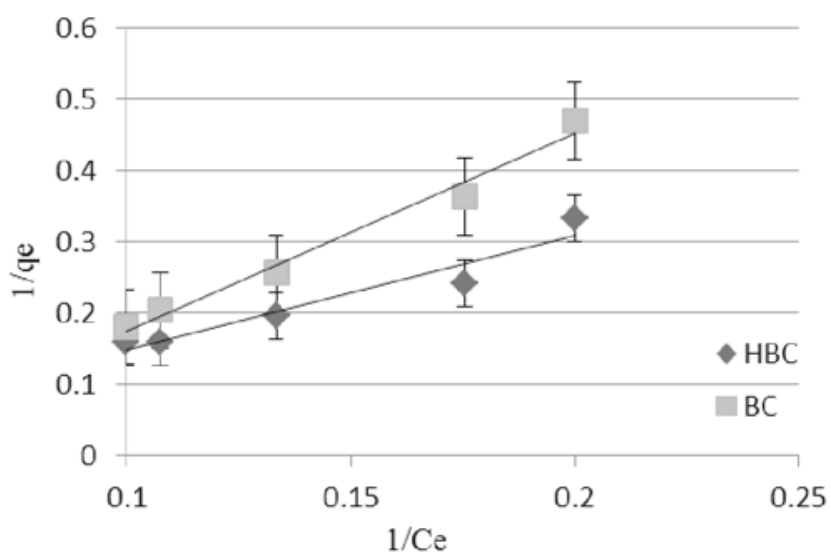

Figure 9. Linearized Langmuir isotherms $\left(1 / \mathrm{q}_{\mathrm{e}}\right)$ vs. $1 / \mathrm{C}_{\mathrm{e}}$ for the adsorption of 2.4-DCP

Freundlich isotherm model describes the logarithmic relation between the energy of sorption and the increase in bending sites. The model can be applied to non-ideal sorption on heterogeneous surfaces as multilayer sorption $^{23}$. The Freundlich equation is:

$\operatorname{Lnq}_{\mathrm{e}}=\mathrm{Lnk}_{\mathrm{f}}+\frac{1}{\mathrm{n}} \mathrm{LnC}_{\mathrm{e}}$
Where $\mathrm{q}_{\mathrm{e}}$ is the equilibrium capacity of sorption in $\mathrm{mg} / \mathrm{g} ; \mathrm{C}_{\mathrm{e}}$ is the equilibrium concentration of the 2.4-DCP in $\mathrm{mg} / \mathrm{L} ; \mathrm{K}_{\mathrm{f}}$ is the sorption capacity coefficient; and $\mathrm{n}$ is a coefficient related to the sorption intensity.

The values of $\mathrm{K}_{\mathrm{f}}$ and $\mathrm{n}$ were obtained from the intercept and the slope of the plots between $\ln \left(\mathrm{q}_{\mathrm{e}}\right)$ versus $\ln \left(\mathrm{C}_{\mathrm{e}}\right)$ in Figure 10 and shown in Table 3 together with other parameters from the Langmuir model.

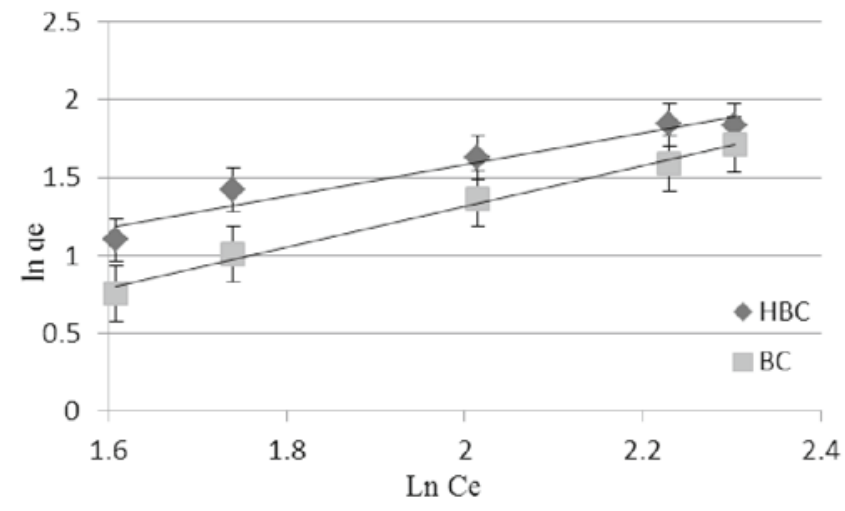

Figure 10. Linearized Freundlich isotherm $\ln \left(q_{e}\right)$ vs. $\ln \left(C_{e}\right)$ for the adsorption of 2.4-DCP

The correlation coefficients $\mathrm{R}^{2}$ for the Freundlich isotherm model were found to be higher than those found from the Langmuir model. Both models thus gave $\mathrm{R}^{2}$ of at least 0.9461 and are both well-fitted for the experimental results. The Freundlich model, however, yielded a better fitting for describing the adsorption of 2.4-DCP onto both adsorbents $\mathrm{BC}$ and $\mathrm{HBC}$ since the $\mathrm{R}^{2}$ obtained were relatively higher and the computed coefficient $\mathrm{n}$ values were less than unity.

\section{Adsorption kinetics}

Adsorption kinetics models, pseudo-first order and pseudo-second order, were used to investigate, at room temperature, the 2.4-DCP adsorption kinetics by adsorbents $\mathrm{BC}$ and $\mathrm{HBC}$.

The pseudo-first order equation can be explained using Lagergren equation:

$\log \left(\mathrm{q}_{\mathrm{e}}-\mathrm{q}_{\mathrm{t}}\right)=\log \left(\mathrm{q}_{\mathrm{e}}\right)-\frac{\mathrm{k}_{1}}{2.303} \mathrm{t}$

Where $\mathrm{q}_{\mathrm{e}}$ and $\mathrm{q}_{\mathrm{t}}$ are the amounts of 2.4-DCP, adsorbed at equilibrium and at time $\mathrm{t}$ in $\mathrm{mg} / \mathrm{g}$, respectively, and $\mathrm{k}_{1}$ is the pseudo-first order rate constant in $\mathrm{g} / \mathrm{mg}^{*} \mathrm{~h}$.

From the first order equation 3 , the values of for 2.4-DCP were calculated and plotted versus time as shown in Figure 11, while the calculated data of the pseudo-first order model are shown in Table 4. If the plotted line is linear with good correlation coefficient, Lagergren equation is appropriate; and it can be clearly seen that $\mathrm{BC}$ did not fare well. Though with respectable $\mathrm{R}^{2}$, HBC does not fit well in this model either, because the $\mathrm{q}_{\mathrm{e}}$ calculated is very different from $\mathrm{q}_{\mathrm{e}}$ experimental.

The pseudo-second order kinetic model equation, based on equilibrium adsorption, is:

Table 4. Adsorption kinetic model rate constants for 2.4-DCP removal by different adsorbents

\begin{tabular}{|c|c|c|c|c|c|c|c|}
\hline \multirow[t]{2}{*}{ Adsorbent } & \multirow{2}{*}{$\begin{array}{c}\mathrm{q}_{\mathrm{eExp}} \\
\mathrm{mg} / \mathrm{g}_{\mathrm{ad}}\end{array}$} & \multicolumn{3}{|c|}{ Pseudo-first order } & \multicolumn{3}{|c|}{ Pseudo-second order } \\
\hline & & $\begin{array}{l}\mathrm{q}_{\mathrm{e}(\mathrm{cal})} \\
\mathrm{mg} / \mathrm{g}\end{array}$ & $\mathrm{k}_{1}$ & $\mathrm{R}^{2}$ & $\begin{array}{l}\mathrm{q}_{\text {e(cal) }} \\
\mathrm{mg} / \mathrm{g}\end{array}$ & $\mathrm{k}_{2}$ & $\mathrm{R}^{2}$ \\
\hline $\mathrm{BC}$ & 5.56 & 4.140 & 0.0260 & 0.7810 & 5.68 & 0.0190 & 0.9925 \\
\hline $\mathrm{HBC}$ & 6.25 & 1.317 & 0.0046 & 0.9421 & 5.90 & 0.0311 & 0.9916 \\
\hline
\end{tabular}




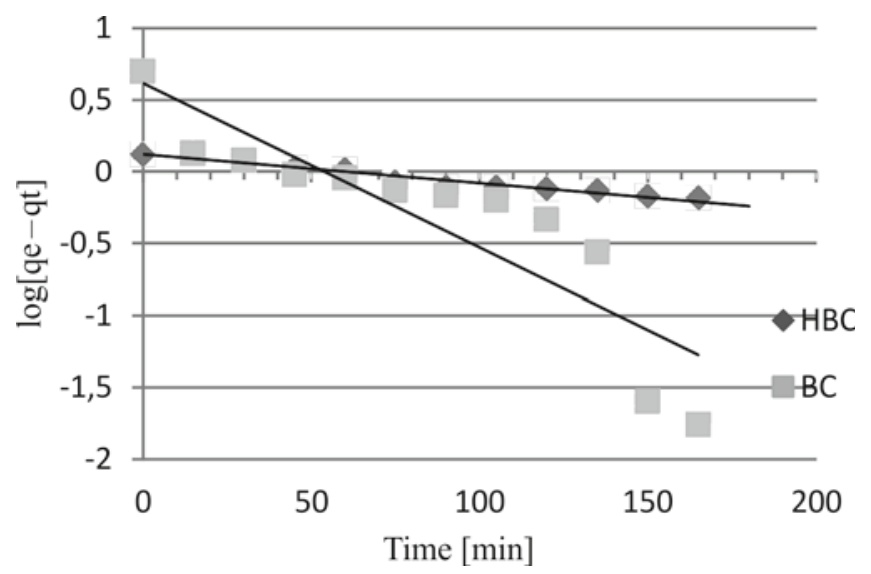

Figure 11. Results from pseudo-first order kinetic model for the removal of 2.4-DCP

$\frac{\mathrm{t}}{\mathrm{q}_{\mathrm{t}}}=\frac{\mathrm{t}}{\mathrm{q}_{\mathrm{e}}}+\frac{1}{\mathrm{k}_{2} \mathrm{q}_{\mathrm{e}}^{2}}$

Where $\mathrm{q}_{\mathrm{e}}$ and $\mathrm{q}_{\mathrm{t}}$ are as described in Equation 1; and $\mathrm{k}_{2}$ is the rate constant of second-order adsorption in $\mathrm{g} / \mathrm{mg} \cdot \mathrm{h}$.

Equation 4 was found to be easier to predict the kinetics behaviour of adsorption over the whole range; the linear plot of $\frac{\mathrm{t}}{\mathrm{q}_{\mathrm{t}}}$ versus $\mathrm{t}$, shown in Figure 12 and in Table 4 as well, was used to find the slope $\frac{1}{\mathrm{q}_{\mathrm{e}}}$, and the intercept $\frac{1}{\mathrm{k}_{2} \mathrm{q}_{\mathrm{e}}^{2}}$. From Table 4, agreements between calculated values of $\mathrm{q}_{\mathrm{e}}$ and experimental values was clear; 5.68 vs. 5.56 for BC, and 5.90 and 6.25 for HBC. Moreover, both correlation coefficients derived from the second-order kinetics model were higher for those obtained from the first-order model. Thus, the second-order kinetics model is proven better than the first-order model to predict and describe the adsorption system of 2.4-DCP onto both adsorbents.

Table 5 details the effectiveness of various adsorbents for adsorption of phenolic compounds. The materials used were compared with more than ten other adsorbents. Out of 16 adsorbents, HBC ranked the 6th best in removal of contaminant, and $\mathrm{BC}$ the 11th best. Isotherms and kinetics investigations also support this. Hence, HBC is effective while BC fares acceptable. As for costs, HAP used in the experiment cost more than USD190 per kg, or USD190.000 per ton, while BC was

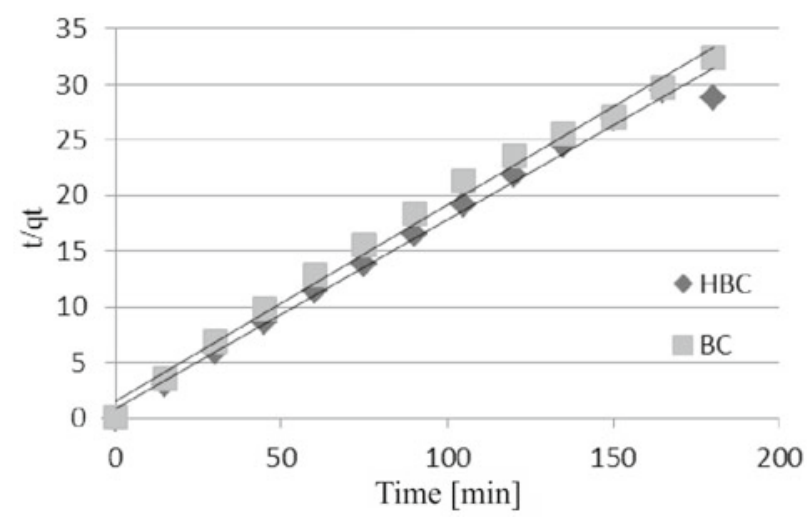

Figure 12. Results from pseudo-second order kinetic model for the removal of 2.4-DCP

reported at USD400-600 per ton in China ${ }^{24}$. The use of $\mathrm{BC}$ and HAP to make HBC thus reduces the cost drastically than using pure HAP. However, the fact that $\mathrm{BC}$ performs better than quite a few others it means $\mathrm{BC}$ is promising to be used, particularly when its low cost is taken into consideration.

\section{CONCLUSION}

The fluidization time was found to reach max at 180 min. In the isotherms investigation it was found that all data fitted well into the Langmuir and Freundlich models, and that the Freundlich model gave a better fit than the Langmuir model. Hence, the Freundlich model is recommended to be used for any further investigations. For the adsorption kinetics, the pseudo-second order model gave a better fit. Comparison of the adsorption efficiency of $\mathrm{BC}$ and $\mathrm{HBC}$ obtained indicated that the two adsorbents have similar isotherm and kinetics behavior. The BC, however, yielded a lower quality value. Both adsorbents were compared for the removal of phenol via adsorption with many others, and $\mathrm{HBC}$ was found to be of good standing, while $\mathrm{BC}$, though in the lower rank, fared acceptably based on its adsorbent capacity and isotherms and kinetics study. $\mathrm{HBC}$ and $\mathrm{BC}$ adsorbents are thus suitable and acceptable for the removal of 2.4-DCP from aqueous solutions at parameters it depended like the $\mathrm{pH}$, the initial concentration of 2.4-DCP, the flow rate of the solution and the time of fluidization. Taken its low cost into consideration, $\mathrm{BC}$ could be regarded as

Table 5. Comparison of phenolic compounds adsorption capacities of different adsorbents

\begin{tabular}{|c|c|c|c|c|}
\hline No & Phenolic compounds & Adsorbents & Capacity [mg/g] & Reference \\
\hline 1 & Phenol & Activated carbon & 49.72 & 28 \\
\hline 2 & P-Chlorophenol & Rice husk char & 36.23 & 27 \\
\hline 3 & Phenol & Multi walled carbon nanotubes & 32.23 & 9 \\
\hline 4 & $2.4 \mathrm{DCP}$ & Palm pith carbon & 19.16 & 25 \\
\hline 5 & Phenol & Palm seed coat activated carbon & 18.30 & 26 \\
\hline 6 & 2.4-DCP & HBC (Hydroxyapatite plus BC) & 16.37 & This study \\
\hline 7 & p-chlorophenol & Rice husk & 14.36 & 27 \\
\hline 8 & 3-Chlorophenol & Rice straw-based carbon & 14.20 & 31 \\
\hline 9 & Phenol & Fly ash & 13.16 & 8 \\
\hline 10 & 2.4-DCP & Mycelial pellets of $P$ chrysosporium & 11.62 & 19 \\
\hline 11 & 2.4-DCP & BC (Bamboo biochar plus Calsium sulphate) & 10.69 & This study \\
\hline 12 & Phenol & Hydroxyapatite nano powders & 10.33 & 12 \\
\hline 13 & Chlorophenol & $\begin{array}{l}\text { Biofilm of } A \text {. viscous supported on } \\
\text { granular activated carbon }\end{array}$ & 9.70 & 30 \\
\hline 14 & P-Chlorophenol & Petroleum coke & 9.34 & 27 \\
\hline 15 & 4-Chlorophenol & Anaerobic granular sludge & 6.32 & 2 \\
\hline 16 & Phenol & Activated coal & 1.48 & 29 \\
\hline
\end{tabular}


a new, moderately effective adsorbent that can be applied in the field of wastewater treatment and industries.

The adsorption capacity for removal of phenol employing $\mathrm{BC}$ was found to be $10.69 \mathrm{mg} / \mathrm{g}$, and that employing the $\mathrm{HBC}, 16.37 \mathrm{mg} / \mathrm{g}$. Both were found to perform better than the metal-removal-efficient but expensive HAP. The two adsorbents, however, have to be replaced after use every time.

\section{ACKNOWLEDGEMENTS}

The authors are grateful to the Prince of Songkla University (PSU) for her financial assistance and support to this research. We would also like to thank the PSU Department of Chemical Engineering and the Discipline of Excellence (DoE) in Chemical Engineering for assistance in the carrying out of needed chemical analyses.

\section{LITERATURE CITED}

1. Tan, I.A.W, Ahmad, A.L. \& Hameed, B.H. (2009). Adsorption isotherms, kinetics, thermodynamics and desorption studies of 2.4.6-trichlorophenol on oil palm empty fruit bunch-based activated carbon. J. Hazard. Mater. 164(2-3), 473-482. DOI: 10.1016/j.jhazmat.2008.08.025.

2. Gao, R. \& Wang, J. (2007). Effects of $\mathrm{pH}$ and temperature on isotherm parameters of chlorophenols biosorption to anaerobic granular sludge. J. Hazard. Mater. 145(3), 398-403. DOI: 10.1016/j.jhazmat.2006.11.036.

3. Hameed, B.H., Chin, L.H. \& Rengaraj, S. (2008). Adsorption of 4-chlorophenol onto activated carbon prepared from rattan sawdust. Desalination 225(1-3), 185-198. DOI: 10.1016/j. desal.2007.04.095.

4. Aksu, Z. \& Akpınar, D. (2000). Modelling of simultaneous biosorption of phenol and nickel(II) onto dried aerobic activated sludge. Sep. Purif. Technol. 21(1-2), 87-99. DOI: 10.1016/ S1383-5866(00)00194-5.

5. Xuequan, Z., Xiankai, W., Huixiang, S. \& Dahui, W. (2009). Adsorption of 2.4-dichlorophenol from aqueous solution onto microwave modified activated carbon: Kinetics and equilibrium. Trans. Tianjin Univ. 15(6), 408-414. DOI: 10.1007/ s12209-009-0071-9.

6. Hamdaoui, O., Naffrechoux, E., Suptil, J. \& Fachinger, C. (2005). Ultrasonic desorption of p-chlorophenol from granular activated carbon. Chem. Eng. J. 106(2), 153-161. DOI: 10.1016/j.cej.2004.10.010.

7. Yan, M., Naiyun, G., Wenhai, C. \& Cong, L. (2013). Removal of phenol by powdered activated carbon adsorption. Front. Environ. Sci. \& Eng. 7(2), 158-165. DOI: 10.1007/ s11783-012-0479-7.

8. Sarkar, M. \& Acharya, P.K. (2006). Use of fly ash for the removal of phenol and its analogues from contaminated water. J. Waste Manage. 26(6), 559-570. DOI: 10.1016/j.wasman.2005.12.016.

9. Abdel-Ghani, N.T., El-Chaghaby, G.A., Farag, S. \& Helal, F.S. (2015). Individual and competitive adsorption of phenol and nickel onto multiwalled carbon nanotubes. J. Adv. Res. 6(3), 405-415. DOI: 10.1016/j.jare.2014.06.001.

10. Wang, J.P., Feng, H.M. \& Yu, H.Q. (2007). Analysis of adsorption characteristics of 2.4-dichlorophenol from aqueous solutions by activated carbon fiber. J. Hazard. Mater. 144(1-2), 200-207. DOI: 10.1016/j.jhazmat.2006.10.003.

11. Mohd Din, A.T., Hameed, B.H. \& Ahmad, A.L. (2009). Batch adsorption of phenol onto physiochemical-activated coconut shell. J. Hazard. Mater. 161(2-3), 1522-1529. DOI: 10.1016/j.jhazmat.2008.05.009.

12. Lin, K., Pan, J., Chen, Y., Cheng, R. \& Xu, X. (2009). Study the adsorption of phenol from aqueous solution on hy- droxyapatite nanopowders. J. Hazard. Mater. 161(1), 231-240. DOI: 10.1016/j.jhazmat.2008.03.076.

13. Downie, A., Crosky, A. \& Munroe, P. (2009). Physical properties of biochar. In: Lehmann, J., Joseph, S. (Eds.). Biochar for environmental management science and technology (13-32). London. UK, Earthscan.

14. Catalano, P.J., Insley, G.M. \& Hess, B. (2007). An in-vivo comparative analysis of the intra-operative properties of injectable calcium phosphate/calcium sulphate based bone cements. Key Eng. Mater. 330-332, 799-802. DOI: 10.4028/www.scientific. net/KEM.330-332.799.

15. Evaniew, N., Tan, V., Parasu, N., Jurriaans, E., Finlay, K., Deheshi, B. \& Ghert, M. (2013). Use of a calcium sulphate-calcium phosphate synthetic bone graft composite in the surgical management of primary bone tumors. Orthopedics 36(2), 216-222. DOI: 10.3928/01477447-20130122-25.

16. Del Rio, J.G., Sanchez, P., Morando, P.J., Cicerone, D.S. (2006). Retention of $\mathrm{Cd}, \mathrm{Zn}$ and $\mathrm{Co}$ on hydroxyapatite filters. Chemosphere 64(6), 1015-1020. DOI: 10.1016/j.chemosphere.2006.02.008.

17. Lin, K., Pan, J., Chen, Y., Cheng, R. \& Xu, X. (2008). Adsorption of phenol from aqueous solution by hydroxyapatite nanopowders. Part II: kinetic, equilibrium and thermodynamic studies, The 2nd ICBBE, 16-18 May 2008 (3119-3122). Shanghai, China: IEEE. DOI: 10.1109/ICBBE.2008.1109.

18. Mowla, D. \& Ahmadi, M. (2007). Theoretical and experimental investigation of biodegradation of hydrocarbon polluted water in a three phase fluidized-bed bioreactor with PVC biofilm support. Biochem. Eng. J. 36(2), 147-156. DOI: 10.1016/j.bej.2007.02.031.

19. Wu, J. \& Yu, H.Q. (2006). Biosorption of 2.4-dichlorophenol from aqueous solution by Phanerochaete chrysosporium biomass: Isotherms, kinetics and thermodynamics. J. Hazard. Mater. 137(1), 498-508. DOI: 10.1016/j.jhazmat.2006.02.026.

20. Calace, N., Nardi, E., Petronio, B.M. \& Pietroletti, M. (2002). Adsorption of phenols by papermill sludges, Environ. Pollu. 118(3), 315-319. DOI: 10.1016/S0269-7491(01)00303-7. 21. Mall, I.D., Srivastava, V.C. \& Agarwal, N.K. (2006). Removal of Orange-G and Methyl Violet dyes by adsorption onto bagasse fly ash-kinetic study and equilibrium isotherm analyses. Dyes Pigm. 69(3), 210-223. DOI: 10.1016/j.dyepig.2005.03.013. 22. Hanen, N. \& Abdelmottaleb, O. (2013). Modeling of the Dynamics Adsorption of Phenol from an Aqueous Solution on Activated Carbon Produced from Olive Stones. Inter. J. Chem. Eng. \& Appl. 4(4), 254-261. DOI: 10.7763/IJCEA.2013.V4.306. 23. Zhang, Z.B., Cao, X.H., Liang, P. \& Liu, Y.H. (2013). Adsorption of uranium from aqueous solution using biochar produced by hydrothermal carbonization. J. Radioanal. Nucl. Chem. 295(2), 1201-1208. DOI: 10.1007/s10967-012-2017-2.

24. Tan, Z., Xiang, J., Su, S., Zeng, H., Zhou, C., Sun, L., Hu, S. \& Qiu, J. (2012). Enhanced capture of elemental mercury by bamboo-based sorbents. J. Hazard. Mater. 239-240, 160-166. DOI: 10.1016/j.jhazmat.2012.08.053.

25. Sathishkumar, M., Binupriya, A.R., Kavitha, D. \& Yun, S.E. (2007). Kinetic and isothermal studies on liquid-phase adsorption of 2, 4-dichlorophenol by palm pith carbon. Bioresour. Technol. 98(4), 866-873. DOI: 10.1016/j.biortech.2006.03.002. 26. Rengaraj, S., Moon, S.H., Sivabalan, R., Arabindoo, B. \& Murugesan, V. (2002). Agricultural solid waste for the removal of organics: adsorption of phenol from water and wastewater by palm seed coat activated carbon. Waste Manage. 22(5), 543-548. DOI: 10.1016/S0956-053X(01)00016-2.

27. Ahmaruzzaman, M. \& Sharma, D.K. (2005). Adsorption of phenols from wastewater, J. Coll. Inter. Sci. 287(1), 14-24. DOI: 10.1016/j.jcis.2005.01.075.

28. Özkaya, B. (2006). Adsorption and desorption of phenol on activated carbon and a comparison of isotherm models. J. Hazard. Mater. 129(1-3), 158-163. DOI: 10.1016/j. jhazmat.2005.08.025. 
29. Vázquez, I., Iglesias, J.R., Marañón, E., Castrillón, L. \& Álvarez, M. (2007). Removal of residual phenols from coke wastewater by adsorption. J. Hazard. Mater. 147(1-2), 395-400. DOI: 10.1016/j.jhazmat.2007.01.019.

30. Quintelas, C., Sousa, E., Silva, F., Neto, S. \& Tavares, T. (2006). Competitive biosorption of ortho-cresol, phenol, chlorophenol and chromium (VI) from aqueous solution by a bacterial biofilm supported on granular activated carbon. Process Biochem. 41(9), 2087-2091. DOI: 10.1016/j.procbio.2006.04.014. 31. Wang, S.L., Tzou, Y.M., Lu, Y.H. \& Sheng, G. (2007). Removal of 3-chlorophenol from water using rice-straw-based carbon. J. Hazard Mater. 147(1-2), 313-318. DOI: 10.1016/j. jhazmat.2007.01.031. 